\title{
The effectiveness of educational podcasts for teaching music and visual arts in higher education
}

\author{
Cheung On Tam* \\ Department of Cultural and Creative Arts, Hong Kong Institute of Education, Hong Kong
}

(Received 31 January 2011; final version received 11 May 2011)

\begin{abstract}
Podcasting is now being used frequently in the higher education sector. Although research has been conducted into the use of podcasting in teaching business, engineering, sciences and languages, little has been done on its use in arts learning. This paper reports on a study that investigated the effectiveness of using podcasts to learn music and visual arts in a teacher-education institution. A total of 128 Year-One to Year-Four students completed a survey and 24 students attended focus-group interviews and gave their feedback on the effectiveness of using podcasts in learning. Generally speaking, the students found the podcasts useful and viewed podcasting as a method which could be used to supplement faceto-face teaching. Results of the study indicated that demonstration of procedures or skills was the most effective type of podcast while reproduction of lecture materials was the least effective. The students suggested that the teachers needed to increase the relevance of the podcast content to what was taught during lessons. The paper concludes with a discussion of the production of effective podcasts and directions for future studies.
\end{abstract}

Keywords: podcasting; podcasts; teaching/learning strategy; arts education; teacher education

\section{Background}

This paper reports on a study that investigated the effectiveness of customised educational materials in the form of podcast files created by teachers. These files included video presentations, demonstrations and edited lectures teaching particular aspects of the music and visual arts courses offered by the Hong Kong Institute of Education in the academic year 2009-2010. The Institute is a tertiary institution dedicated to providing professional teacher education for those who wish to teach at early childhood, primary or secondary levels in Hong Kong. Feedback collected from students by means of a survey and interviews offered information on the effectiveness of using podcasts to learn and learners' views on what constitutes an effective educational podcast. The term 'podcasting' was first proposed by journalist Ben Hammersley in a February 2004 article of The Guardian (Copley 2007). It is a portmanteau word blending 'iPod' and 'broadcast' (Sutton-Brady et al. 2009). Podcasting is a method of distributing a digital media file or a series of files over the Internet for playback on portable media players such as iPods or personal computers (Lazzari 2009). Users may subscribe to a feed that links automatically to the most

\footnotetext{
*Email: cotam@ied.edu.hk

RLT 2012. (C) 2012 C.O. Tam. Research in Learning Technology is the journal of the Association for Learning Technology (ALT), a UK-based professional and scholarly society and membership organisation. ALT is registered charity number 1063519. http:// www.alt.ac.uk/. This is an Open Access article distributed under the terms of the Creative Commons "Attribution 3.0 Unported (CC BY 3.0)" license (http://creativecommons.org/licenses/by/3.0/) permitting use, reuse, distribution and transmission, and reproduction in any medium, provided the original work is properly cited. 
recent materials, or download the files manually from the Internet. All podcasts used in this study were movie files in MPEG-4 format, which is a multimedia container format that allows the storage and presentation of digital video, digital audio, texts and images. For the distribution of the podcasts in this study, it was carried out through the iTunes program by providing Really Simple Syndication (RSS) feeds to students. First, a series of podcasts was saved on the distributor's server. Students then downloaded the podcasts using the 'subscribe' function of iTunes by adding a uniform resource locator feed. Teachers periodically uploaded newly produced podcasts to the server and students would get the updated files automatically each time they started iTunes. Files were stored locally on students' computers or other devices and also could even be used offline. The iTunes program also provided one special function - the 'iTunes U'-whereby students could search and download podcasts from universities, museums and educational institutions all over the world on topics related to the course.

\section{Podcasting in higher education}

Among the general public and in particular among young people, web-based applications of sharing information, images and videos through YouTube, Facebook or Twitter have been increasingly used (Lenhart et al. 2010). The launch of 'iTunes U' in American universities including Yale, MIT, Stanford and Berkeley by Apple Computer, Inc. also shows that digital learning is becoming important in higher education and that technologies such as podcasting are being used more often (Lonn and Teasley 2009). Most studies on the use of podcasting in higher education have focused on describing the results of pilot projects (e.g. Edirisingha et al. 2007) and the benefits and shortcomings of using podcasts from the perspectives of university lecturers and students (e.g. Sutton-Brady et al. 2009).

According to Tohill's study (2008), podcasts have been used most frequently in teaching engineering and science $(33.3 \%)$, computer and information technology $(33.3 \%)$, and business and law $(13.3 \%)$. The number of studies on applications of podcasting in arts learning is quite small. Kerstetter (2009) suggests that the use of podcasts enriches the music classroom in the dissemination of course content, provision of supplementary course materials, recording of visiting lecturers and provision of campus updates in music courses. In researching how technology can be employed in art education, Buffington (2008) asked students to create podcasts on specific works of art. He found that students not only learnt about the technology of podcasting, but also engaged in deep discussions about the meanings of the artworks.

\section{Types of podcast currently in use}

Educational podcasts at university level can be divided into four categories based on their purposes of production, namely, teaching-driven (e.g. record of lecture), servicedriven (e.g. library tour), marketing-driven (e.g. student recruiting advertisement) and technology-driven (e.g. support provided by university technology/media departments) (Harris and Park 2008). Rosell-Aguilar (2007) further classified teaching-driven podcasts into teacher initiated and student initiated. For the former, there are 'lecture podcasts' and 'supplementary podcasts'. Lecture podcasts are simply records of lectures (Copley 2007) while supplementary podcasts are materials that support learning in relation to core learning materials (Lee and Chan 2007). 
Nie (2006) lists various types of supplementary podcast that are usually used in higher education, including pre-lecture materials, feedback to students on assignments, records of interviews, supplementary topics that have not been covered in lectures, explanation of difficult areas of courses, and information for field activities. Examples of student-initiated podcasts include assignments, discussions between students, interviews of specialists, as well as records and reflections on learning activities (Abt and Barry 2009).

\section{Effectiveness of podcast learning}

There are two major approaches to investigating the effectiveness of podcast learning. The first approach analyses the effects through user self-report while the second makes use of experimental designs and focuses on the examination and test results of students. In general, studies which have adopted the first approach suggest that podcasts can enhance learning. Anzai (2007) studied the use of podcasts to improve English learning for English as a foreign language students. The study found that podcasts were beneficial to learning because of special features they possess: for instance, the accumulation of chronologically ordered contents with RSS, mobile learning and free subscription. Bongey, Cizadlo, and Kalnbach (2006) surveyed 246 students on a biology course and found that the students perceived podcasts to be useful in increasing their understanding of material covered in the lectures. Lane (2006) examined health sciences students' experiences of using podcasts; $70 \%$ of the participants agreed that the podcasts supported their learning and were helpful in preparation for examinations. In Clark et al.'s (2007) survey of 30 postgraduate marketing students, $96 \%$ indicated that podcasting enhanced their learning and $89 \%$ stated that podcasting helped them actively engage in learning.

However, the results of experimental studies on the effectiveness of podcasts are varied. Kurtz, Fenwick, and Ellsworth (2007) found a significant improvement in the final project grades of those students who used podcasts. By contrast, some researchers found a similar effect on student learning when using other review materials and did not find that the use of podcasts had a significant effect in enhancing student grades (Copley 2007; Lazzari, 2009). Abt and Barry (2007) adopted an experimental research design in the delivery of a physiology course. They found no significant difference between the podcast group and the control group. Lakhal, Hager, and Pascot (2007) compared the final marks of students who used podcasts and those who did not. The results suggested that podcasts have a positive effect on student satisfaction but no effect on student performance.

The present study subscribed to the first approach and collected data basically through user self-report survey and user interview. The focus of the study was on evaluating students' general learning experience of using podcasts.

\section{Methodology}

The aims of this study were to investigate the effectiveness of using podcasts to learn music and visual arts and to identify the characteristics of an effective educational podcast from the perspective of students. A total of 184 students enrolled in eight music or visual arts courses participated in the study. An evaluation survey and focus-group interviews were used to collect students' feedback. The survey was administered to all students in the last session of each 
course and three students from each course were randomly selected to attend the focus-group interview. A total of 128 students completed the survey and 24 students attended the interview. The results of the survey provided a general picture of how the students evaluated the effectiveness of using podcasts to learn. The focus-group interview allowed the researcher to explore the data collected from the survey in an interactive way. During the interview, semi-structured questions were asked and students commented on the podcasts offered in their courses and provided reasons for their ratings.

\section{Participants and procedures}

At the beginning of the study, teachers teaching the eight courses developed podcasts taking into account the content, schedule and assessment of the course. These courses focused on topics of music or visual arts, including pedagogy, arts making and appreciation, arts administration, use of computer software and research skills in the arts. The podcasts produced were mainly supplementary podcasts and could be categorised into three types: informational (I), demonstration (D), and activity or assignment related (AAR). Informational podcasts delivered references, handouts or PowerPoint presentations in video format with audio commentary by the teachers. Most of the content on the informational podcasts had already been covered by the teachers during the lessons and they were basically developed for student revision purposes. Demonstration podcasts showed the procedures or skills involved in running computer software such as Band in a Box, SPSS and Adobe InDesign. Teachers either captured the computer screen and their voice during demonstrations in lessons or developed a video specifically to show the steps involved in using the software.

Students watched these podcasts when they tried the software application after lessons. For podcasts related to learning activities and assignments, students were required to respond to questions asked in the podcast, complete worksheets after watching the podcast or provide feedback by producing their own podcasts. All participants were full-time students studying for a Bachelor of Education or a Postgraduate Diploma in Education. They came from various years of study and over half of them were specialising in music or visual arts. Table 1 shows the courses and related podcast types.

Table 1. Podcast type and course title.

\begin{tabular}{lll}
\hline Podcast type & & \multicolumn{1}{c}{ Course title } \\
\hline Informational & - & \multicolumn{1}{c}{ Art Management and Culture Policy (management) } \\
& - & Music Technology and Creative Music Making (technology) \\
Demonstration & - & Print-making (print) \\
& - & Foundation Computer-based Music Technology (computer) \\
Activity or & - & Vonours Project (project) \\
Assignment related & - & $\begin{array}{l}\text { Pedagogical Approaches to Music Teaching and Learning } \\
\text { (pedagogical) }\end{array}$ \\
& - & $\begin{array}{l}\text { Sculpture: An Evolution of Body Consciousness and Aesthetics } \\
\text { (sculpture) }\end{array}$ \\
\hline
\end{tabular}




\section{Survey statements and interview questions}

At the beginning of the survey, four general questions related to the ways in which students downloaded and watched the podcasts were asked. They are presented in Table 2.

In order to evaluate the effectiveness of the podcasts used on the course they attended, the students were asked to rate six statements according to a five-point Likert-scale, with values ranging from One (strongly disagree) to Five (strongly agree). The statements were constructed based on the findings of past studies (Fernandez, Simo, and Sallan 2009; Sutton-Brady et al. 2009; Evans 2008). The six statements are presented in Table 3.

Three students from each course were randomly selected and attended separate focus-group interviews after the last lesson. Nine questions were asked to elicit students' feedback:

(1) What do you think about the advantages and disadvantages of using podcasting in learning?

(2) Do you think using podcasts is an effective way of learning? Why?

(3) Do you think using podcasts will help to enhance academic achievement?

(4) Which kinds of learning needs can podcasting address more effectively than face-to-face teaching? What is the main difference between learning from podcasts and face-to-face teaching?

(5) How do podcasts assist and supplement face-to-face teaching?

(6) Do you expect podcasts to be used in more courses in the future?

(7) Will you use podcasts in your future teaching?

(8) Can you describe what constitutes an effective educational podcast?

(9) What would you suggest to improve/assist/support podcast learning?

\section{Data analysis}

The SPSS statistical computer software was used to analyse the results of the survey. A reliability test was conducted before the analysis. Cronbach's Alpha $(\alpha>0.7)$, a coefficient measuring internal consistency of the scores obtained from the survey, was ensured. An ANOVA was carried out after the reliability test to determine whether there were any significant differences between the three groups of students: those who received (1) informational, (2) demonstration and (3) learning activity or assignmentrelated podcasts. The Scheffe test (the most conservative test) and the Bonferroni test (a less conservative test) would be conducted as a follow-up procedure if significant differences were found. Both tests are methods for adjusting significance levels so as to prevent data from being incorrectly interpreted as statistically significant.

For the focus-group interviews, the students' responses were audio recorded and a complete typed transcript was made. To ensure anonymity, the name of each student was replaced with a code. In order to identify and classify the target variables,

Table 2. General questions on podcast watching.

G1

G2

G3

G4
What device did you use for watching the podcasts?

On average, how many times did you watch each podcast?

Where do you usually watch the podcasts?

An effective educational podcast should be__ minutes long. 
Table 3. Evaluative statements on the effectiveness of podcast learning.

\begin{tabular}{ll} 
S1 & Podcast increases my interest in learning \\
S2 & I like podcasting because I can learn at my own pace \\
S3 & Podcast is a convenient way to learn \\
S4 & Podcast is an effective way to revise the course content \\
S5 & Podcast aids in assignment preparation \\
S6 & The visual effects in the podcasting increase my interest in learning \\
\hline
\end{tabular}

categories were developed and the related data were allocated to available typological categories before the generalisation of the data. The interviews were analysed in the following three areas:

(1) Students' attitudes towards learning with podcasts;

(2) Comparing face-to-face learning with learning from podcasts;

(3) Students' expectations of effective educational podcasting.

\section{Findings}

A total of $128(70 \%)$ out of 184 students completed the questionnaire. Of the 128 respondents, $24(19 \%)$ students replied that had not watched any of the podcasts. Only feedback from students who had watched the podcasts at least once $(n=104)$ was used in the analysis of the results. Three students from each course, totalling 24 students $(n=24)$, were interviewed. Cronbach's Alpha was 0.87 , which was higher than the level of acceptance.

\section{Comparing the effectiveness of different types of podcast}

Overall, the students rated podcast provision of demonstrations of procedures or skills as the most effective and considered informational podcasts as the least effective. Podcasts related to learning activities or assignments were rated in the middle. The details are presented in Table 4.

A One-way ANOVA, a statistical test used to compare means of different groups, was conducted to explore any differences in effectiveness rating among the three groups of podcasts. Significant differences were found between the evaluation of the effectiveness of informational podcasts and the other two types, $F(2,101)=22.297, p<0.05$. However, there was no significant difference between the evaluation of the effectiveness of podcasts integrating information with learning activities and assignments and that of podcasts demonstrating procedures or skills. In the following discussion, the capital letters I, D and AAR

Table 4. Mean scores for the effectiveness of different types of podcast.

\begin{tabular}{lcccc}
\hline Types of podcast & Number of students & Number of podcasts & Mean & SD \\
\hline Informational & 37 & 28 & 3.12 & 0.73 \\
Demonstration & 23 & 17 & 3.88 & 0.47 \\
Activity or Assignments & 44 & 8 & 3.85 & 0.38 \\
related & & & & \\
\hline
\end{tabular}

Note: Rounded to 2 sig. fig. 
are used to represent informational, demonstration, and activities or assignmentrelated podcasts, respectively. One word in smaller letters is selected from the course title and is used to refer to the course. S1, S2 or S3 refers to the student being interviewed.

Demonstrations of procedures or skills received the highest rating among the three types of podcast. Students indicated how these podcasts helped them to learn:

By following the steps in the podcast, I can run the [SPSS] test smoothly at home. (D, project, S1)

Although the lecturer has explained or demonstrated the skills during lessons, we have to try and see if we really understand them. We can ... follow ... and pause whenever we like. (D, computer, S2)

Students reported that podcasts were especially helpful on courses that taught something abstract and were not easy to explain with notes alone. The video clips with verbal explanations in the podcasts helped the students to comprehend the content more clearly:

It is obvious that podcasts are more effective than notes if teachers are teaching something about lyrics or editing the lyrics of old songs, as podcasts can show both audio and visual information at the same time. (AAR, pedagogical, S3)

With regard to podcasts integrated with learning activities or assignments, students rated these as more effective than "pure" informational podcasts, as shown in their interview responses:

I don't think it is particularly effective if the lecturer only asks me to watch the podcasts on my own, but it will be better if the lecturer can provide me with some follow-up activities or discussions. (AAR, sculpture, S2)

Although informational podcasts were generally rated as the least effective, students commented that they could use them to review lecture content, and they thought it was a time-saving and convenient way to learn:

The advantage is that I can learn at any time and any place I want, so I can make better use of my free time. (I, print, S2)

\section{An effective educational podcast from students' perspectives}

In the interviews, the students commented on the content, relevance, length, presentation and technical aspects of an effective educational podcast.

\section{Considering the nature of the content}

The students highlighted the nature of the content as being an important factor in deciding whether podcasts should be used. In their opinion, not all kinds of course content should be produced in podcast form:

It depends on the content ... if it is something factual or something like historical knowledge, I don't think podcast is a good choice. (D, computer, S3)

This is dependent on the subject matter. If it requires a deep level of logical thinking, say like designing a [teaching] plan, I think it should be presented in notes, and podcasts are not so helpful in this case. (AAR, pedagogical, S2) 


\section{Showing the relevance to lesson learning}

Students pointed out that podcasts would be less effective if they could not see the relevance to their lessons. Short informational podcasts which summarised the main points of a lesson were suggested:

The podcast should be related to the content taught in lessons and state clearly to which part it is related. (I, technology, S2)

I think a podcast should be a further explanation of the lecture content; it should focus on the main points... (D, project, $\mathrm{S} 3)$

\section{Dividing into small sections and adding instructions}

As students could not interact with their teachers directly when they were using podcasts, they stated that it was important to have clear instructions on how they have to respond and how to complete follow-up activities. They also thought that adding titles, subtitles, captions and sections in the podcast might help:

The teacher should explain what we need to do clearly at the beginning of the podcast. Short summaries could be used to highlight the points if the podcast contains more than one section. (D, communication, S3)

Titles and subtitles should also be added so that we can find what we need more easily, just like reading a book...(AAR, sculpture, S3)

\section{Optimal length}

A question was asked in the survey to investigate the optimal length of an educational podcast. Ninety-five students $(85.5 \%)$ preferred podcasts that lasted for less than 15 minutes (Table 5). This finding was supported by the data obtained from the interviews:

I think a podcast should not be too long and should be limited to 10 minutes. I feel lost if it is too long and I don't know which part I should watch... (I, print, S2)

\section{Presentation with audio and visual effects}

With regard to the presentation of podcasts, the students suggested that more audio and visual effects such as animation could be added. Teachers also needed to pay attention to their voice and tone:

I agree that learning materials will be more attractive if some visual effects are used. (I, management, S1)

It is too boring to listen to the lecture again and I think more pictures and clips should be added. (AAR, sculpture, S1)

The tone! It will be even more boring if the teacher talks in a dull tone of voice. (AAR, sculpture, S2)

Table 5. Preferred length of podcasts.

\begin{tabular}{lccccc}
\hline & $\begin{array}{c}\text { Less than } 5 \\
\text { minutes }\end{array}$ & $\begin{array}{c}5-15 \\
\text { minutes }\end{array}$ & $\begin{array}{c}16-30 \\
\text { minutes }\end{array}$ & $\begin{array}{c}\text { Half an hour } \\
\text { to an hour }\end{array}$ & $\begin{array}{c}\text { Longer than } \\
\text { an hour }\end{array}$ \\
\hline $\begin{array}{l}\text { An effective educational } \\
\text { podcast should } \\
\text { be_ minutes long. }\end{array}$ & $24 \%$ & $61.5 \%$ & $12.5 \%$ & $1.9 \%$ & $0 \%$ \\
\hline
\end{tabular}




\section{Dissemination and downloading}

The students thought that an effective podcast should be easy to access and download:

I think it is a must to teach students how to use podcasts and how to access them. (AAR, pedagogical, S1)

... it would be good if students only had to access one website in order to find all the podcasts they needed. (D, communication, S3)

\section{Discussion}

\section{Effective use of different types of podcast to supplement face-to-face teaching}

Concerning the content of podcasts, the students' rating of demonstrations as the most effective can be explained in several ways. An examination of those courses that provide demonstrations (graphic design, music creation and research methods) reveals that the application of software constituted an important part of the course. In learning these applications, students had to practise repeatedly in order to become familiar with the skills and apply them in assignments or graduation projects. In many of these podcasts, procedures were explained audibly and visually. This is supported by Brittain et al.'s (2006) findings that information-dense course content with a heavy reliance on visual images is better podcasted. Actively utilising the multimedia technology in presenting information, the podcasts have created a multisensory learning experience for students.

The importance of using podcasts to review demonstrations was also highlighted by the students who participated in the present study, as well as by the students of biomedical subjects who took part in Brittain et al.'s study (2006). The reviewing function of podcasts allows students to concentrate on what the lecturer said instead of trying to record all the details presented in lessons. With podcasts, students can trace information missed and catch up with the progress of teaching by self-learning.

Compared to demonstrations, students rated informational podcasts as less effective. The students' responses suggest that if the material presented in the podcast is simply a repetition of that presented in the lecture, the podcast is not useful. For most of the courses in this study, informational podcasts were used to provide supplementary learning materials and students watched them only if they felt it necessary. Some of these podcasts were records of individual student or group work while many of them were PowerPoint or notes with audio commentary that had been gone through during lessons. In some cases, students preferred to have hard copies of handouts because they could make notes directly on the handouts and this made a deeper impression on them during revision. Although previous studies have noted that the reproduction of lectures may lead to benefits (Brittain et al. 2006) such as providing the lecture for those who did not attend and a record to support revision (Evans 2008), the students who took part in the current study suggested that the reproduction of a lecture in the form of a podcast is not useful. In fact, researchers point out that the strategy of simply reproducing lectures in podcasts is in conflict with learning theories that advocate richer and more active learning experiences for learners (Middleton 2009). Another reason that may account for the low rating of informational podcasts is the time of conducting the survey and the interviews. As they were conducted in the last session of each course, the students by that time had not yet recognised the benefits of using podcasts as revision aids for final assignment preparation. 
However, podcasts integrating information with learning activities or assignments obtained higher ratings when compared to "pure" informational podcasts. In these cases, students were able to see the connection between the podcasts and their learning or assessment. They felt involved and were motivated to watch the podcasts. The students also mentioned the importance of explicitly indicating the relevance of the podcasts to their studies. This demonstrates that the effectiveness of using podcasts to learn is determined not only by the unique advantages of podcasting itself, but also by teachers' teaching strategies. An integration of podcasting with existing pedagogies will facilitate the effective use of podcasts. It is suggested that teachers can relate podcasts to classroom teaching with follow-up discussions, learning tasks and assessment.

\section{Appropriate length and use of multimedia technology in podcasting}

In this study, we found that students were in favour of relatively short podcasts and they preferred podcasts to be an edited summary of lessons, further explanations of difficult concepts or a quick review of what was taught in lessons. A majority of the students suggested that an educational podcast should be at most 15 minutes long. This finding is in line with the findings of previous studies that the length of podcasts should range between 5 and 20 minutes (Anzai 2007; Chan and Lee 2005; Muppala and Chan 2007).

The increasing use of multimedia technology in education has allowed teachers to create learning resources that appeal to students (Sutton-Brady et al. 2009) and stimulate their learning motivation (Belanger 2007). In the opinion of the students who participated in this study, audio and visual effects could be added to podcasts to make them more attractive. The students commented that the use of animation in podcasts increased their interest in learning and that in some cases they preferred watching clips to reading words. This supports Evans' (2008) findings that university students today are more receptive to learning using podcasts than traditional learning materials. This is also related to the environment in which students have grown up. Campbell (2005) suggests that current university students are familiar with working in "rich media". Students not only have a good understanding of multimedia but also use them as a "language" on a daily basis. In a study of 183 undergraduate students, Howard, Ellis, and Rasmussen (2004) also note that multimedia with their video, audio and graphics effects can capitalise on the contemporary rich media environment and contribute significantly to learning. However, for teachers, creating podcasts with appealing visual effects or animations inevitably implies more workload. In this connection, technical and human resource support from the teaching institution becomes indispensable for the successful implementation of podcast learning.

\section{Technical issues}

Hew (2009) reviewed past studies on the barriers to using podcasts and found that unfamiliarity with podcasts and technical problems in accessing and downloading were common problems in podcast learning. During the interview conducted for the current study, a number of students expressed difficulties in subscribing to the podcast files, especially at the beginning stage of the study. This is the major disadvantage associated with podcast learning explicitly mentioned by students. The students also mentioned that they preferred to go to one website to access the podcasts instead of 
navigating through many different sites. Students nowadays have a better understanding and experience of using multimedia tools, but the use of podcasts or the RSS feed is still relatively new to them. The findings also reflected the importance of choosing a platform for uploading and downloading and of technical support being provided throughout the learning process. The suggestions from the students supported past findings. To ensure the same learning opportunity for all students in using podcasts and to lessen the influence exerted by differences in levels of computer literacy, introductory sessions on what podcasting is, how to download podcasts from the selected platform, and how to fix common technical problems should be provided.

\section{Conclusions and suggestions for further studies}

In general, the findings suggested that podcasts helped the students who took part in this study in achieving personalised learning. They perceived podcasting as a platform that provided supplementary learning materials to support face-to-face teaching. Among the three types of podcast that have been identified, demonstration and activity or assignment-related podcasts are more effective than informational podcasts. Podcasts that demonstrate the application of skills and content that requires audio and visual explanation are well received. Simply converting lecture PowerPoints or handouts into podcast files does not work well. Students strongly suggested that instead of duplicating course content that has been taught in lessons in podcasts, teachers should integrate podcasts with lesson learning in the form of follow-up discussions, completion of assessment-related tasks or extension of lesson learning activities. The study has provided educators with an initial categorisation of podcasts according to their functions, purposes and their relative effectiveness in teaching music and visual arts courses. Future podcast producers may work on this taxonomy and create finer classifications addressing the different nature of podcasts and their effectiveness.

This paper has pointed out some of the factors that teachers may take into account when deciding whether and how podcasts should be used. Further exploration of other factors, such as the relationship between podcast effectiveness and student educational levels, the use of podcasts in learning different types of subject matter, and the relationship between podcasts and student digital competency, is needed. There is still little description of how to combine podcasting successfully with existing pedagogies and there is no evidence-based model to follow, in either strategy or practice. There is also a lack of research on supporting podcast learning at an institutional level and there is a pressing need to develop a strategic plan for mobile learning. These aspects of podcast learning present possible directions for future studies.

\section{References}

Abt, G. \& Barry, T. (2007) 'The quantitative effect of students using podcast in a first year undergraduate exercise physiology module', Bioscience Education e-Journal, vol. 10, pp. 1-9.

Abt, G. \& Barry, T. (2009) A strategy for using podcasts for teaching and learning in the Biosciences, Centre for Bioscience, The Higher Education Academy, University of Leeds, Leeds, [online]. Available at: http://www.bioscience.heacademy.ac.uk/resources/projects/ barry.aspx

Anzai, Y. (2007) 'Empowering English learning utilizing podcasts', in Proceedings of World Conference on E-Learning in Corporate, Government, Healthcare, and Higher Education 2007, ed. G. Richard, AACE, Chesapeake, VA, pp. 10-15. 
Belanger, Y. (2007) Summary of Duke Digital Initiative Instructional Programs 2006-2007, Duke University, Durham, NC.

Bongey, S. B., Cizadlo, G. \& Kalnbach, L. (2006) 'Explorations in course-casting: podcasts in higher education', Campus-Wide Information Systems, vol. 23, no. 5, pp. 350-367.

Brittain, S., et al. (2006) 'Podcasting lectures: formative evaluation strategies helped identify a solution to a learning dilemma', Educause Quarterly, vol. 29, no. 3, pp. 24-31.

Buffington, M. L. (2008) 'Creating and consuming Web 2.0 in art education', Computers in the Schools, vol. 25, no. 3-4, pp. 303-313.

Campbell, G. (2005) 'There's something in the air: podcasting in education', Educause Review, vol. 40, no. 6 (Novembr/December), pp. 32-46.

Chan, A. \& Lee, M. J. W. (2005) 'An MP3 a day keeps the worries away: exploring the use of podcasting to address preconceptions and alleviate pre-class anxiety amongst undergraduate information technology students', in Good Practice in Practice. Proceedings of the Student Experience Conference 5-7 $7^{\text {th }}$ September'05, eds D. H. R. Spennemann \& L. Burr, Charles Sturt University, Wagga Wagga, NSW, pp. 59-71.

Clark, S., Sutton-Brady, C., Scott, K. M. \& Taylor., L. (2007) 'Short podcasts: the impact on learning and teaching', in Proceedings of mLearn Conference 2007, eds A. Austin \& J. Pearce, University of Melbourne, Australia, pp. 285-289.

Copley, J. (2007) 'Audio and video podcasts of lectures for campus-based students: production and evaluation of student use', Innovations in Education and Teaching International, vol. 44, no. 4, pp. 387-399.

Edirisingha, P., et al. (2007) 'Podcasting to provide teaching and learning support for an undergraduate module on English language and communication', Turkish Online Journal of Distance Education, vol. 8, no. 3, pp. 87-107.

Evans, C. (2008) 'The effectiveness of m-learning in the form of podcast revision lectures in higher education', Computers and Education, vol. 50, no. 2, pp. 491-498.

Fernandez, V., Simo, P. \& Sallan, J. M. (2009) 'Podcasting: a new technological tool to facilitate good practice in higher education', Computers and Education, vol. 53, no. 2, pp. 285-392.

Harris, H. \& Park, S. (2008) 'Educational usages of podcasting", British Journal of Educational Technology, vol. 39 , no. 8 , pp. 548-551.

Hew, K. F. (2009) 'Use of audio podcast in K-12 and higher education: a review of research topics and methodologies', Education Tech Research Dev, vol. 57, no. 3, pp. 333-357.

Howard, W., Ellis, H. \& Rasmussen, K. (2004) 'From the arcade to the classroom: capitalizing on students' sensory rich media preferences in disciplined-based learning', College Student Journal, vol. 38, no. 3, pp. 431-440.

Kerstetter, K. (2009) 'Educational applications of podcasting in the music classroom', Music Educators Journal, vol. 95, no. 4, pp. 23-26.

Kurtz, B. L., Fenwick, J. B., Jr. \& Ellsworth, C. C. (2007) Using podcasts and tablet PCs in computer science, [online]. Available at: http://portal.acm.org/citation.cfm?doid= 1233341.1233428

Lakhal, S., Hager, K. \& Pascot, D. (2007) 'Evaluation of the effectiveness of podcasting in teaching and learning', in Proceedings of World Conference on E-Learning in Corporate, Government, Healthcare, and Higher Education 2007, eds G. Richards \& S. Carliner, AACE, Chesapeake, VA, pp. 6181-6188.

Lane, C. (2006) Podcasting at the UW: an evaluation of current use, The Office of Learning Technologies, University of Washington, [online]. Available at: http://www.washington. edu/lst/research_development/papers/2006/podcasting_report.pdf

Lazzari, M. (2009) 'C Creative use of podcasting in higher education and its effect on competitive agency', Computers and Education, vol. 52, no. 1, pp. 27-34.

Lee, M. J. W. \& Chan, A. (2007) 'Pervasive, lifestyle-integrated mobile learning for distance learners: an analysis and unexpected results from a podcasting study', The Journal of Open and Distance Learning, vol. 22, no. 3, pp. 201-218.

Lenhart, A., et al. (2010) 'Social media and young adults', Pew Internet and American Life Project, [online]. Available at: http://www.pewinternet.org/Reports/2010/SocialMedia-and-Young-Adults.aspx

Lonn, S. \& Teasley, S. D. (2009) 'Podcasting in higher education: what are the implications for teaching and learning?', The Internet and Higher Education, vol. 12, no. 2, pp. 88-92. 
Middleton, A. (2009) 'Beyond podcasting: creative approaches to designing educational audio', Research in Learning Technology, vol. 17, no. 2, pp. 143-155.

Muppala, J. K. \& Chan, K. K. (2007) 'Podcasting and its use in enhancing course content', in CATE' 07 Proceedings of the $10^{\text {th }}$ IASTED International Conference on Computers and Advanced Technology in Education, ed. V. Uskov, ACTA Press, Anaheim, CA, pp. 492-495.

Nie, M. (2006) The pedagogical perspectives of mobile learning, [online]. Available at: http:// hdl.handle.net/2381/407

Rosell-Aguilar, F. (2007) 'Top of the pods - in search of a podcasting "pedagogy" for language learning', Computer Assisted Language Learning, vol. 20, no. 5, pp. 471-492.

Sutton-Brady, C., et al. (2009) 'The value of using short-format podcasts to enhance learning and teaching', Research in Learning Technology, vol. 17, no. 3, pp. 219-232.

Tohill, K. (2008) 'I podcast, you podcast, together we podcast: podcasting as a learning tool in second language classrooms', in Proceedings of Society for Information Technology and Teacher Education International Conference 2008, eds K. McFerrin, et al., AACE, Chesapeake, VA, pp. 3645-3650. 